\title{
2D and 3D QSAR of Benzimidazole Analogues as Novel HIV-1 Non Nucleoside Reverse Transcriptase Inhibitors
}

\author{
Shital Patil ${ }^{*}$ Kalyani Asgaonkar, Trupti Chitre, Vedika Bhat, Sayali Ethape, Anagha Sujalegaonkar, \\ Sudeep Bhalekar
}

Department of Pharmaceutical Chemistry, A.I.S.S.M.S. College of Pharmacy, Near RTO, Kennedy Road, Pune-411001, Maharashtra, INDIA.

\begin{abstract}
Context: Acquired Immuno Deficiency Syndrome (AIDS) is a viral disease caused by Human Immunodeficiency Virus. There is an urgent need to identify newer NNRTIs active against these mutant strains Literature survey has revealed that $\mathrm{N} 1$-aryl-benzimidazole analogues have significant potential as HIV-1. Aim: Pharmacophore optimization of Benzimidazole nucleus as non-nucleoside reverse transcriptase inhibitors using Two Dimensional (2D) and Three Dimensional (3D) OSAR. Material \& Method: Studies were carried out using V-Life MDS Softwre(4.3 version) using Multiple Linear Regression (MLR) Analysis and Simulated Annealing k Nearest Neighbor Molecular Field Analysis (SAkNN MFA). Result \& Discussion: The model generated for 2D QSAR showed significant statistical parameters such as $\mathrm{r} 2=0.8847, \mathrm{q} 2=0.7448$. The model generated for 3D QSAR showed significant statistical parameter such as $q 2=$ of 0.6695 . Conclusion: QSAR studies indicated the requirement of certain physicochemical parameters and hydrophobic groups for better Anti HIV activity.
\end{abstract}

Key words: Molecular Modeling, 2d Qsar, 3d Qsar, Benzimidazole, Anti -HIV.

\section{INTRODUCTION}

Acquired Immuno Deficiency Syndrome (AIDS) is a viral disease caused by Human Immunodeficiency Virus type I (HIV type I) in which in-built defense system of body breaks down completely. HIV-1 virus has more virulence and transmiability than HIV-2 and is prevalent globally. Currently, the most commonly used anti-HIV therapy is through the parallel use of drugs that belongs either to the class of nucleoside/ nucleotide reverse transcriptase inhibitors (NRTIs/NTRIs) and non-nucleoside reverse transcriptase inhibitors (NNRTIs), protease or entry inhibitors and HIV integrase inhibitors.

NNRTIs are structurally diverse group which are more specific and less toxic compounds and binds a specific and allosteric site to the viral enzyme Reverse Transcrip- tase (RT). NNRTIs non-competitively inhibit RT enzyme, block its mechanism and make it unable to produce a viral DNA. Nevertheless, to date drugs used to treat AIDS under NNRTIs for anti-AIDS therapy are Nevirapine, Delaviridine, Efavirenz, Etravirine and more recently Rilpivirine. The therapeutic efficacy of NNRTIs has been limited by the emergence of drugresistant mutants (such as Y188C, Y181C, $\mathrm{K} 103 \mathrm{~N}$, and L100I) and the severe side effects. Therefore there is an urgent need to identify newer NNRTIs active against these mutant strains with improved pharmacokinetic profile. ${ }^{1,2}$

N1-aryl-benzimidazole analogues have shown a variety of biological activities such as antihistaminic, anti-HIV, anti hepatitis C to name a few. ${ }^{3-5}$ Literature survey has
Submission Date: 12-12-2016; Revision Date: 14-03-2017; Accepted Date: 10-04-2017

DOI: 10.5530ijper.51.2s.58 Correspondence: Shital Patil, Department of Pharmaceutical Chemistry, A.I.S.S.M.S. College of Pharmacy, Near RTO, Kennedy Road, Pune-411001, Maharashtra, INDIA.

Tel: 9881203150

E-mail: sheetalnikam1212@ yahoo.co.in

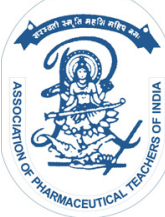

www.ijper.org 
revealed that N1-aryl-benzimidazole analogues have significant potential as HIV-1 non-nucleoside reverse transcriptase inhibitors. ${ }^{6-12}$ Molecular modeling study is an approach that is used to focus on the development of optimal models through variable selection and statistical methods to taper down to highly effective New Chemical Entities (NCE's). Quantitative Structure-Activity Relationships (QSAR) is a widely accepted tool used for finding associations between chemical structures and biological activity. ${ }^{13}$ Thus in the present study we have focused on development of Two Dimensional (2D) and Three Dimensional (3D) QSAR studies using Multiple Linear Regression (MLR) Analysis and Simulated Annealing k Nearest Neighbor Molecular Field Analysis (SA-kNN MFA), respectively for a series of N1 aryl- benzimidazole 2-substituted as novel HIV-1 Non Nucleoside Reverse Trascriptase Inhibitors (NNRTI's).

\section{MATERIALS AND METHODS}

\section{Computational Details}

All the computational studies were carried out using the V-Life sciences, Molecular Design Suite (MDS) version 4.3. ${ }^{14,15}$ Molecules were drawn in Chem. Draw Ultra 8.0 and geometry optimization was done using the standard Merck molecular force field (MMFF). The geometry of each molecule was further optimized. The initial conformations were selected and minimized using the Powell method until the root-mean-square deviation 0.001 $\mathrm{kcal} / \mathrm{mol} \AA$ was achieved. ${ }^{16,17}$

\section{Data Set}

A data set (27molecules) of N1 -aryl- benzimidazole derivatives with varied chemical and biological activities, reported by Monforte Anna-Maria et al for anti-HIV activity, was considered for the QSAR studies. ${ }^{1}$ Biological activity expressed in effective concentration (EC) was converted into the corresponding $\mathrm{pEC}_{50}\left(\mathrm{pEC}_{50}=-\log \right.$ $\left(\mathrm{EC}_{50}\right)$ values (Table 1). To obtain a predictive QSAR model validation was carried out for which the entire data set was divided into Training and test set using manual selection method. For 2D QSAR 17 molecules were considered in the training set and 5 molecules were considered in test set. For 3D QSAR 20 molecules were considered in the training set and 2 molecules were considered in test set. Uni--Column statistics were generated for uniform representation of the molecules in the training and test sets. While selection of molecules in the training set and test set a care was taken in such a way that biological activities of all compounds in test set lie within the maximum and minimum value range of biological activities of training set of compounds. ${ }^{11}$

\section{D QSAR studies}

Different models were generated for the 2D-QSAR study using MLR method. The MLR analysis was used to correlate biological activities with physicochemical properties. Various 2D descriptors like topological, physicochemical, alignment-independent, and atomtype count descriptors were generated for the geometrically optimized structures. These generated descriptors were further reduced by removing the invariable columns. This was followed by refinement in the selection of descriptors by using the correlation matrix which considers correlation between descriptor with activity as well as correlation between descriptor-descriptor. Variable selection method stepwise forward backward together with MLR regression method was employed to generate statistically significant model.

\section{D QSAR studies}

3D QSAR studies were carried out by $\mathrm{kNN}$ MFA method using $\mathrm{SA}$ as variable selection method. The selected series of compounds were aligned using the template-based alignment method and template used for alignment is depicted in (Figure 1). Generated models were cross validated using Leave-one-out (LOO) procedure. Different steric, electronic and hydrophobic points were generated and the model generated was evaluated based on different statistical parameters.

\section{RESULT AND DISCUSSION}

2D QSAR: The model generated for 2D QSAR showed significant statistical parameters such as $\mathrm{r}^{2}=0.8847$, $\mathrm{q}^{2}=0.7448$ (Table 2). 2D QSAR equation was generated along with the fitness plot that indicated the dependence of the biological activity on various different types of the descriptors (Figure 2, Figure 3).

The regression equation obtained is represented as follows:

pEC $_{50}=1.0899$ T_N_Cl_3-1.1787 SssOCount -0.4212 $\mathrm{X} \log \mathrm{P}-0.4189 \mathrm{X}$ comp Dipole - 4.8498.

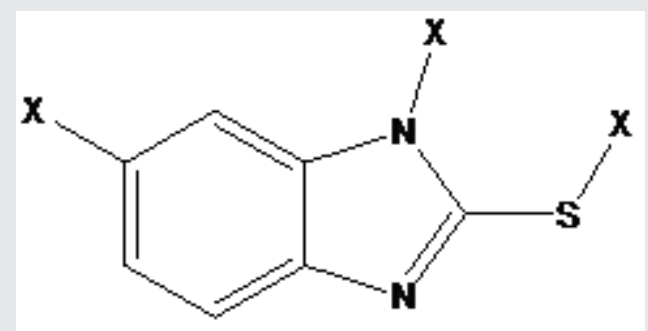

Figure 1: Template used for 3D QSAR. 


\section{Contribution of descriptors}

T_N_Cl_3- This descriptor signifies that chlorine should be separated from Nitrogen by 3 bond distance. It is a positively contributing descriptor with a contribution of $35.06 \%$.
SssOCount- This descriptor defines the total no of Oxygen connected with 2 single bonds. Negative Contribution of this descriptor was $37.91 \%$.

$\mathrm{X} \log \mathrm{P}-\mathrm{This}$ is atom based evaluation of $\log \mathrm{P}$. This descriptor signifies ratio of solute concentration in octanol and water and generally termed as Octanol

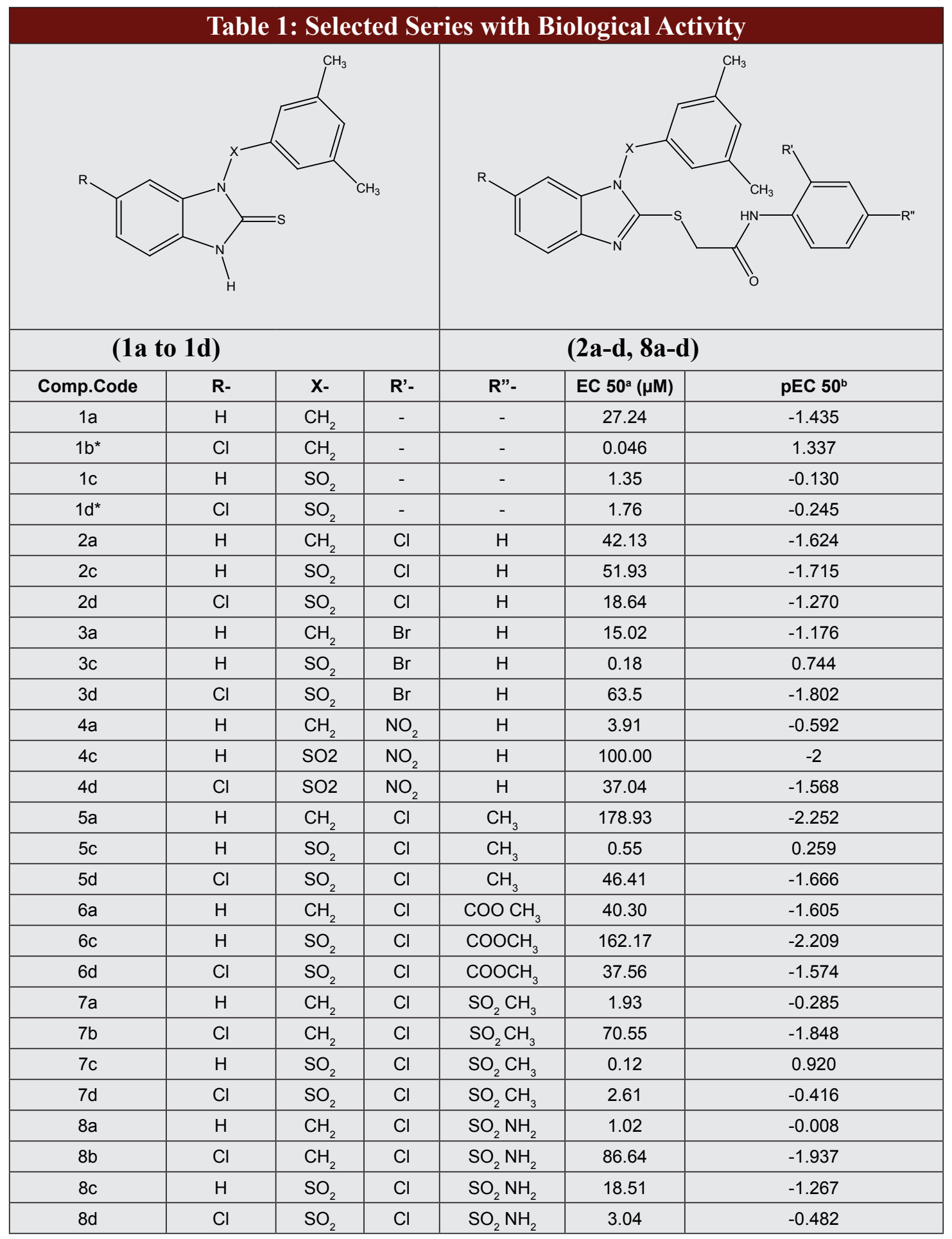

$a=E C 50-$ Effective concentration, $\quad b=E C_{50}=-\log \left(E C_{50}\right)$ 


\begin{tabular}{|c|c|c|}
\hline \multirow{2}{*}{ Statistical Data } & 2D QSAR & 3D QSAR \\
\hline & (MLR) & (SA-KNN MFA) \\
\hline$r^{2}$ & 0.8847 & -- \\
\hline$r^{2} S E$ & 0.2487 & -- \\
\hline$q^{2}$ & 0.7448 & 0.6695 \\
\hline$q^{2} S E$ & 0.3795 & 0.4643 \\
\hline Pred_r $r^{2}$ & 3.0658 & -0.5580 \\
\hline Pred_r ${ }^{2} S E$ & 2.0141 & 1.1611 \\
\hline F-Test & 8.6880 & -- \\
\hline $\mathrm{N}$ & 21 & 20 \\
\hline $\begin{array}{l}\text { K Nearest } \\
\text { neighbor }\end{array}$ & -- & 2 \\
\hline Contributing descriptors & $\begin{array}{l}\text { Negatively Contributing-XlogP, XcompDipole, } \\
\text { SssOCount Positively Contributing-T_N_Cl_3 }\end{array}$ & $\begin{array}{l}\text { Negatively contributing: S_2606,E_2400,S_269 } \\
\text { Positively contributing: } \mathrm{H} \_941, \mathrm{H} \_753, \mathrm{H} \_95\end{array}$ \\
\hline
\end{tabular}

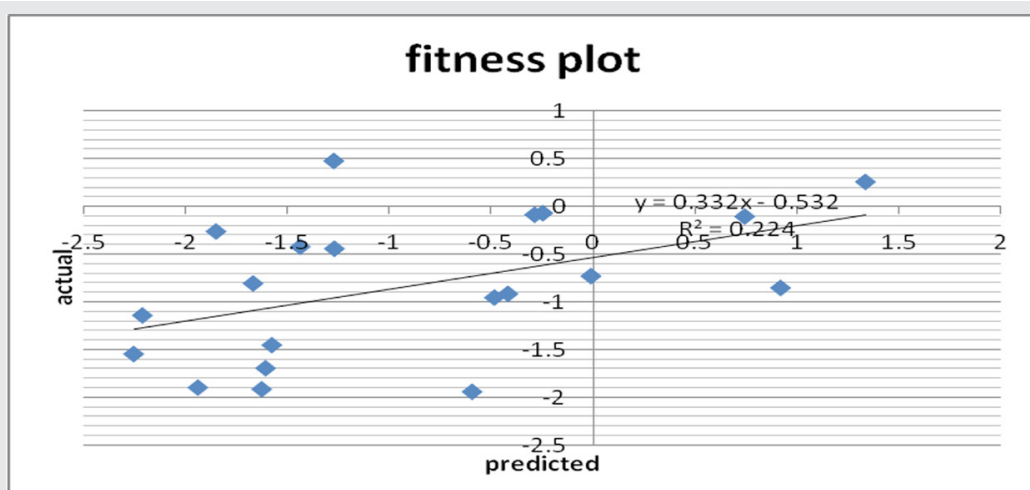

Figure 2: Fitness plot- graph of predicted activity vs observed activity for 2D QSAR .

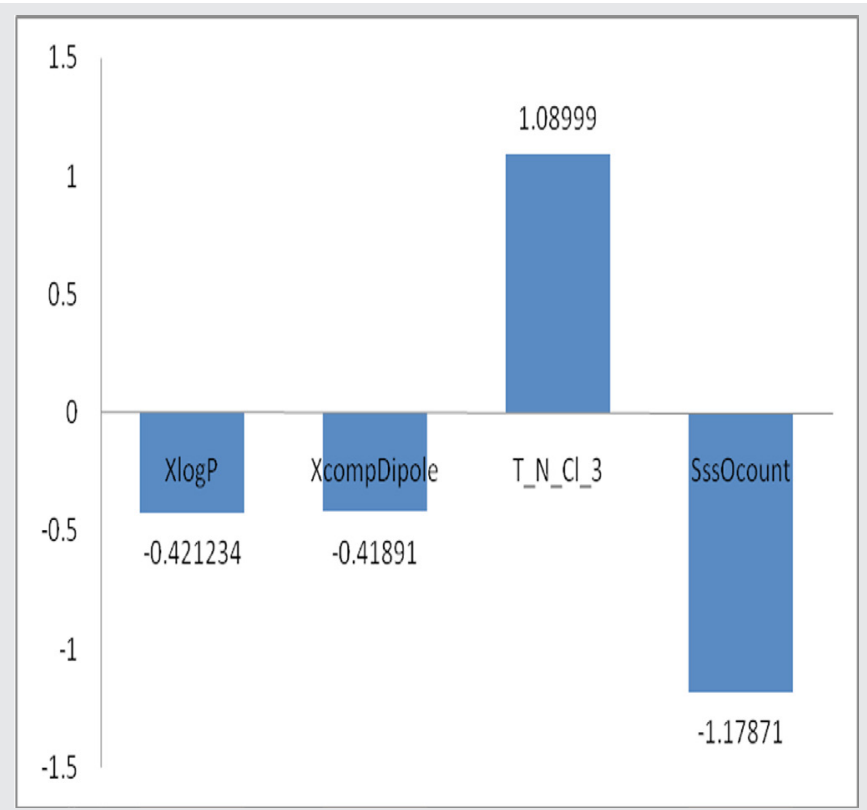

Figure 3: Contribution plot of Descriptors for 2D QSAR. 


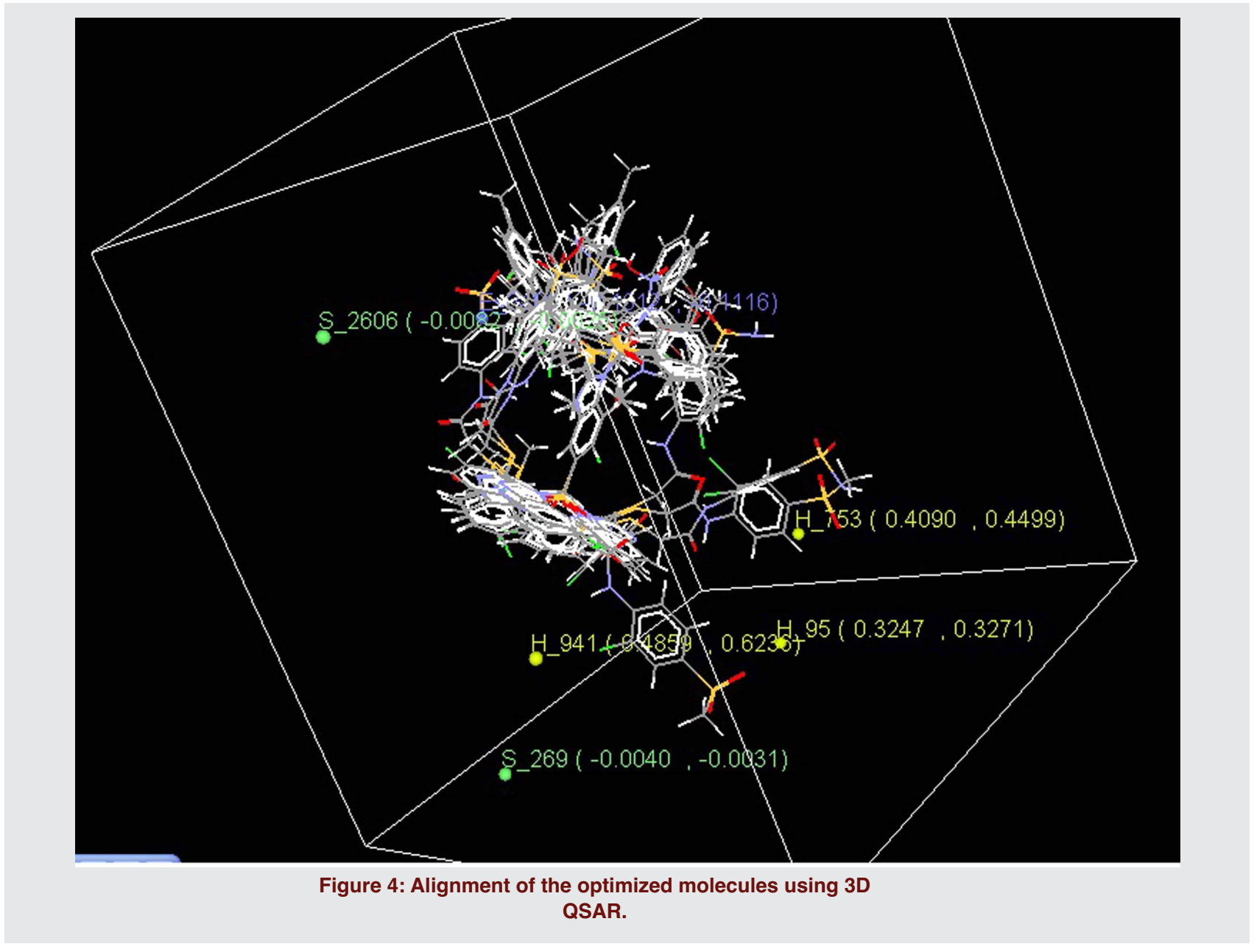

Water partition Coefficient. Negative Contribution of this descriptor was $13.54 \%$.

X comp Dipole- X Component of Dipole moment. Negative Contribution of this descriptor was $13.47 \%$.

The higher frequency of occurrence of positively contributing descriptors in NCE's may lead to increase in biological activity whereas the negatively contributing descriptors should be avoided while designing the NCE's.

\section{D QSAR}

The energy minimized molecules were properly aligned on the selected template (Figure 4). The model generated for 3D QSAR showed significant statistical parameter such as $\mathrm{q}^{2}$ of 0.6695 (Table 2).

\section{Interpretation of 3D QSAR studies}

In 3D QSAR studies, 3D data points generated around Benzimidazole pharmacophore were used to optimize the electrostatic and steric requirements of the Benzimidazole nucleus for anti-HIV activity. The points generated in KNN MFA 3D QSAR model are negatively contributing S_2606,E_2400,S_269 and Positively contributing H_941,H_753,H_95 (Figure 3b).

These points suggested the significance and requirement of less electrostatic, steric and more hydrophobic groups for maximum biological activity of Benzimidazole analogues.

The points generated around the pharmacophore were used to correlate chemical nature of substituents around benzimidazole ring with their observed activity.

\section{CONCLUSION}

The present study was aimed to derive $2 \mathrm{D}$ and $3 \mathrm{D}$ QSAR models for optimization of pharmacophore to identify key structural fragments required for anti HIV activity. Results obtained from statistically significant models indicated the requirement of physicochemical descriptors like T_N_Cl_3 which is positively contributing to the anti-HIV activity from 2D QSAR whereas 3D QSAR gave an insight to the importance of hydrophobic groups that increase the biological activity. 


\section{ACKNOWLEDGEMENT}

Authors are thankful to Dr. Ashwini. R. Madgulkar, Principal AISSMS College Of Pharmacy, Pune, India of our institute for continuous motivation, support, and for providing the necessary infrastructure to carry out this work.

\section{CONFLICT OF INTEREST}

The authors declare no conflicts of interest.

\section{ABBREVIATIONS USED}

HIV type I: Human Immunodeficiency Virus type I; QSAR: Quantitative structure-activity relationship; MLR: Multiple Linear Regression; kNN MFA: k Nearest Neighbor Molecular Field Analysis; AIDS: Acquired Immuno Deficiency Syndrome; HIV-2; NRTIs/NTRIs: Nucleoside/nucleotide reverse transcriptase inhibitors; NNRTIs: Non-nucleoside reverse transcriptase inhibitors; NCE's: New Chemical Entities; MDS: Molecular Design Suite; MMFF: Merck molecular force field; EC: Effective concentration; SA: Simulated annealing.

\section{REFERENCES}

1. Monforte A, Ferro S, Luca L, Surdo G, Morreale F, Pannecouque C, et al. Design and synthesis of N1 -aryl- benzimidazole 2-substituted as novel HIV-1 Non Nucleoside Reverse Transcriptase Inhibitors. Bio-organic and Medicinal Chemistry. 2014;22(4):1459-67. https://doi.org/10.1016/j.bmc.2013.12.045 ; PMid:24457088.

2. Murugesan V, Makwana N, Suryawanshi R, Saxena R, Tripathi R, Paranjape $\mathrm{R}$, et al. Rational design and synthesis of novel thiazolidin-4-ones as nonnucleoside HIV-1 reverse transcriptase inhibitors, Bioorganic and Medicinal Chemistry. 2014;22:3159-70. https://doi.org/10.1016/j.bmc.2014.04.018 ; PMid:24794742.

3. Gadhave R, Vichare V, Joshi S. Synthesis and Biological Evaluation for Antihistaminic activity of N1-Alkyl-2(N4- Alkyl/Aryl piperazinyl methyl) Benzimidazole derivatives $\mathrm{R}(\mathrm{S})$. Asian Journal of Research in Chemistry 2012;5(7):918-21.

4. Roth $T$, Morningstar M, Boyer P, Hughes S, Buckheit R Jr, Michejda C. Synthesis and biological activity of novel nonnucleoside inhibitors of HIV1 reverse transcriptase. 2-Aryl-substituted benzimidazoles. Journal of Medicinal Chemistry. 1997;40(26):4199-207. https://doi.org/10.1021/ jm970096g ; PMid:9435891.

5. Ding K, Wang A, Boerneke M, Dibrov S, Hermann T. Aryl-substituted aminobenzimidazoles targeting the hepatitis $C$ virus internal ribosome entry site . Bioorganic and Medicinal Chemistry. 2014;24(14):3113-7. https://doi. org/10.1016/j.bmcl.2014.05.009 ; PMid:24856063 PMCid:PMC4096041.

6. Barreca M, Rao A, De Luca L, Zappala M, Monforte A, Pannecouque MGC, et al. Computational strategies in discovering novel non-nucleoside inhibitors of HIV-1 RT. Journal of Medicinal Chemistry. 2005;48(9):3433-7. https://doi. org/10.1021/jm049279a ; PMid:15857150.

7. Barreca M, Rao A, De Luca L, Zappala M, Monforte A, Maga G, et al. Discovery of novel benzimidazolones as potent non-nucleoside reverse transcriptase inhibitors active against wild-type and mutant HIV-1 strains. Bioorganic and Medicinal Chemistry. 2007;17(7):1956-60. https://doi. org/10.1016/j.bmcl.2007.01.025; PMid:17276064.

8. Monforte A, Logoteta P, Ferro S, De Luca L, Iraci N, Monforte AM, et al. Design, synthesis, and structure-activity relationships of 1,3-dihydrobenzimidazol2-one analogues as anti-HIV agents. Bioorganic and Medicinal Chemistry. 2009;17(16):5962-7. https://doi.org/10.1016/j.bmc.2009.06.068 PMid:19616956.

9. Monforte A, Rao A, Logoteta P, Ferro S, De Luca L, Barreca M, et al. Novel N1-substituted 1,3-dihydro-2H-benzimidazol-2-ones as potent nonnucleoside reverse transcriptase inhibitors. Bioorganic and Medicinal Chemistry. 2008;16(15):7429-35. https://doi.org/10.1016/j.bmc.2008.06.012; PMid:18585918.

10. Barreca M, De Luca L, Iraci N, Rao A, Ferro S, Maga G, et al. Structurebased pharmacophore identification of new chemical scaffolds as nonnucleoside reverse transcriptase inhibitors. Journal of Chemical Information and Modelling. 2007;47(2):557-62. https://doi.org/10.1021/ci600320q ; PMid:17274611.

11. Monforte A, Logoteta P, De Luca L, Iraci N, Ferro S, Maga G, et al. Novel 1,3-dihydro-benzimidazol-2-ones and their analogues as potent nonnucleoside HIV-1 reverse transcriptase inhibitors. Bioorganic and Medicinal Chemistry. 2010;18(4):1702-10. https://doi.org/10.1016/j.bmc.2009.12.059 ; PMid:20097079.

12. Samuele A, Crespan E, Vitellaro S, Monforte A, Logoteta P, Chimirri A, et al. Slow binding-tight binding interaction between benzimidazol-2-one inhibitors and HIV-1 reverse transcriptase containing the lysine 103 to asparagine mutation. Antiviral Research. 2010;86(3):268-75. https://doi.org/10.1016/j. antiviral.2010.03.008; PMid:20307579.

13. Pawar V, Lokwani D, Bhandari SV, Mitra D, Sabde S, Bothara K, et al. Design of potential reverse transcriptase inhibitor containing Isatin nucleus using molecular modeling studies. Bioorganic and Medicinal Chemistry. 2010;18(9):3198-211. https://doi.org/10.1016/j.bmc.2010.03.030 ; PMid:20381364.

14. V Life MDS; Molecular Design Suite version 3.5. V-life Sciences Technologies Pvt. Ltd., Pune, India, 2004. www.vlifesciences.com

15. Inamdar P, Bhandari S, Sonawane B, Hole A, Jadhav C. Structure Optimization of Neuraminidase Inhibitors as Potential Anti-Influenza (H1N1 Inhibitors) Agents Using QSAR and Molecular Docking Studies. Iranian Journal of Pharmaceutical Research. 2014;13(1):49-65. PMid:24734056 PMCid:PMC3985258.

16. Halgren TA. Merck molecular force field. II. MMFF94 van der Waals and electrostatic parameters for intermolecular interactions. Journal of Computational Chemistry. 1996;17(5-6):520-52. https://doi.org/10.1002/ (SICI)1096-987X(199604)17:6<520::AID-JCC2>3.3.CO;2-W.

17. Ohtawara K, Teramae H. Study on optimization of molecular structure using Hamiltonian algorithm. Chemical Physics Letters. 2004;390(1):84-8. https:// doi.org/10.1016/j.cplett.2004.03.088. 




\section{About Authors}

\section{SUMMARY}

- Molecular modelling approach was used to design novel Benzimidazole analogues as anti HIV agents. The present study was aimed to derive 2D and 3D QSAR models for optimization of pharmacophore to identify key structural fragments required for anti HIV activity. Two Dimensional (2D) and three dimensional (3D) Quantitative structure-activity relationship (QSAR) studies were carried out for a series containing benzimidazole nucleus with Anti-HIV Activity using Multiple Linear Regression (MLR) and k Nearest Neighbor Molecular Field Analysis (kNN MFA)method respectively. Results obtained from statistically significant models were used to derive the optimized benzimidazole pharmacophore for better Anti HIV activity.

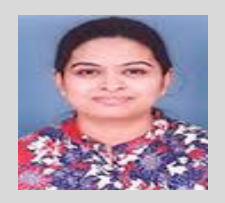

Shital Patil- M.Pharm: Assistant Professor in Dept. of Pharmaceutical chemistry. Her area of research includes drug design, synthesis of Anti HIV and Anti TB entities.

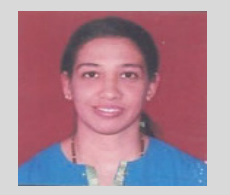

Kalyani Asgaonkar- M.Pharm: Assistant Professor in Dept. of Pharmaceutical chemistry. Her area of research includes drug design, synthesis of Anti HIV and Anti TB entities.

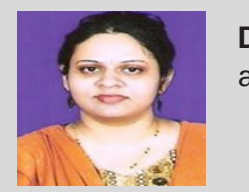

Dr.Trupti Chitre- M.Pharm, Ph.D: Associate Professor in Dept. of Pharmaceutical chemistry. Her area of research includes drug design, synthesis of Anti HIV and Anti TB entities.

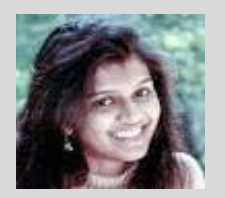

Vedika Bhat: Undergraduate students of AISSMS College of Pharmacy.

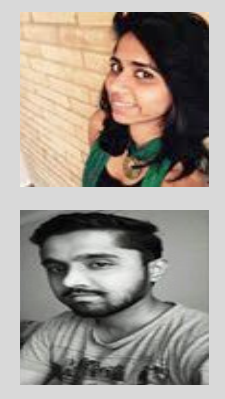

Sayali Ethape: Undergraduate students of AISSMS College of Pharmacy.

Sudeep Bhalekar: Undergraduate students of AISSMS College of Pharmacy.

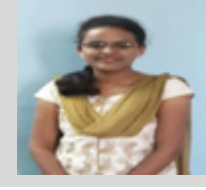

Anagha Sujalegaonkar: Post graduate student in department of Pharmaceutical chemistry in AISSMS College of Pharmacy.

Cite this article: Patil S, Asgaonkar K, Chitre T, Bhat V, Ethape S, Sujalegaonkar A, Bhalekar S. 2D and 3D QSAR of Benzimidazole Analogues as Novel HIV-1 Non Nucleoside Reverse Transcriptase Inhibitors. Indian J of Pharmaceutical Education and Research. 2017;51(2s):122-8. 